Int. J. Electrochem. Sci., 16 (2021) Article ID: 210220

International Journal of

ELECTROCHEMICAL

SCIENCE

www.electrochemsci.org

\title{
Highly Sensitive and Selective Detection of Glucose by Electrochemical Sensor Based on Mesoporous Silica Coated Graphene Oxide Nanosheet
}

\author{
Weisong Sun ${ }^{1,2}$, Sirong $\mathrm{Yu}^{1,}{ }^{*}$, Jianwen Liu ${ }^{2}$, Yang Ke ${ }^{2}$, Jian Sun ${ }^{2}$ \\ ${ }^{1}$ School of Materials Science and Engineering, China University of Petroleum, Qingdao, Shandong \\ 266580, China \\ ${ }^{2}$ Shandong Special Equipment Inspection Institute, Zibo, Shandong 255000, China \\ "E-mail: ysrsd1022@126.com
}

doi: $10.20964 / 2021.02 .51$

Received: 5 October 2020 / Accepted: 25 November 2020 / Published: 31 December 2020

\begin{abstract}
This study focused on preparation and electrochemical study of mesoporous silica coated graphene oxide nanosheet electrode for determination of glucose. Graphene oxide nanosheets (GO) were prepared using modified Hummer's method on glassy carbon electrode (GCE) and then were chemically coated with mesoporous silica nanoparticles $\left(\mathrm{SiO}_{2}\right)$. The morphology and structure of synthesized electrodes were studied by SEM and XRD analyses. The differential pulse voltammetry (DPV) and amperometry techniques were applied for electrochemical studies of glucose sensors. Results of structural characterization showed that the GO was prepared in a crumpled, stacked, expanded nanosheet structure. After coating with $\mathrm{SiO}_{2}, \mathrm{SiO}_{2}$ nanoparticles were deposited on the GO nanosheets. DPV investigations revealed that the sensor was stable and sensitive for determination of glucose. The amperometry results exhibited that the linear range, limit of detection and sensitivity of sensor were estimated 0 to $900 \mu \mathrm{M}, 0.03 \mu \mathrm{M}$ and $0.97086 \mu \mathrm{A} / \mu \mathrm{M} \mathrm{cm} \mathrm{cm}^{2}$, respectively, which indicate the limit of detection and sensitivity were more competitive and superior than previous reports of graphene and $\mathrm{SiO}_{2}$ based glucose sensors in literatures. The selectivity and ability of the prepared sensor were examined for detection of glucose in the real human serum sample which indicates the $\mathrm{SiO}_{2} / \mathrm{GO} / \mathrm{GCE}$ was greatly reliable in practical glucose detection.
\end{abstract}

Keywords: Glucose detection; Electrochemical sensor; $\mathrm{SiO}_{2}$ nanoparticles; Graphene oxide nanosheets; Real human serum sample

\section{$\underline{\text { FULL TEXT }}$}

(C) 2021 The Authors. Published by ESG (www.electrochemsci.org). This article is an open access article distributed under the terms and conditions of the Creative Commons Attribution license (http://creativecommons.org/licenses/by/4.0/). 